\title{
AN AGGREGATE MODEL OF MANUFACTURING FIRM MIGRATION
}

\author{
Stephen P. Coelen, Robert A. Nakosteen, and Michael A. Zimmer*
}

\section{Introduction}

Economists have long maintained an active interest in the geographic mobility of economic factors of production, giving most of their attention to human mobility patterns perhaps because of the availability of data in this area. The recent application of serveral micro data bases has characterized a movement of the research on human migration from studies of aggregate migration flows (at which level most of the early studies focused) to studies of micro migration decisions. In summarizing recent work in human migration, Greenwood (1985) alludes to this development:

Models . . . have frequently been estimated with aggregate data relating both to migrants and to the determinanats of migration. (R)esearch has, with increasing frequency, relied upon microdata that have appeared during the last 10 years for verification of associated hypotheses.

Only recently has there developed a significant literature in the area of business or firm mobility, and this literature has followed a different path than that taken by research on human migration. Empirical studies quantifying the location decisions of firms have focused on micro level decisions from the beginning; current studies continue this emphasis. Carlton (1983), for example, studied the location decisions of new branch plants in three narrowly defined (4-digit Standard Industrial Classification code) industries, locating in small geographic areas (SMSA's). Nakosteen and Zimmer (1987) also used individual firm data, studying the relocation decision of 2-digit manfacturing firms among states. Both studies make use of estimating techniques tailored to micro data applications (logit and probit, respectively).

We are not aware of any studies of firm migration at the aggregate level. While such studies might now seem a retrogression in the literature on factor mobility, we believe that there is an important role to be served in the building of such models.

\footnotetext{
*Coelen and Nakosteen are from the School of Management, University of Massachusetts/Amherst, and Zimmer is from the School of Business Administration, University of Evansville. The authors benefited from comments made by the referees of this joumal.
}

Economists study factor mobility to gauge the allocative efficiency of the price system in correcting imbalances in factor supply and demand, and macro studies are needed to evaluate how much of the total factor flows are explained by economic imbalances. Micro level studies determine only if the direction of movement is "right" in the sense of responding as expected to various economic stimuli. They yield little data on the overall efficiency of aggregate factor flows. The building of aggregate models of firm migration ultimately will facilitate the introduction of capital mobility components in models of regional development.

Aggregate models of firm mobility also can provide policy-related information that is complementary to the results of micro analysis. The results of a study such as Carlton's can provide very specific information to address policy questions, such as the impact of a large force of engineers on the location of a high technology branch plant. However, such studies are silent on the issues of a more general nature, such as the aggregate flow of entrepreneurial factors toward or away from, e.g., specific regional high wage areas. The goal of this paper is to provide the theoretical framework and an initial test, of such an aggregate model.

The paper is organized in the following manner. Section II provides a theoretical framework for the study. In Section III, a data base which allows the examination of firms' patterns of migration is identified and discussed. Section IV contains the specification of a model of firm migration. Section $V$ presents the results of estimating the model; Section VI concludes the paper.

\section{Theoretical Framework}

Our theoretical framework includes three components. First, relying on previous work by Greenhut (1951 and 1952) on the theory of plant location, we outline the type of factors which would lead a firm to initially chose a particular location for a plant. These factors include both pecuniary determinants (including supply and market access factors) and nonpecuniary determinants (i.e. psychic income motivations). We describe how such factors might lead a firm to change its location, showing how a firms's profit maximizing goal interacts with changes in its environment, leading the firm to move to a new location. Finally, we describe the type of model that would serve to explain firm migration, given our theoretical framework. 
The theory of plant location has developed along two fairly distinct, though not contradictory, lines. One of the lines emphasizes the search for the least cost site and generally abstracts from demand. A purely competitive environment is assumed for sellers who are relatively homogeneously spread over space but with factor costs differing among locations. In this situation, plant location is the outcome of a leastcost site. Under certain conditions one firm can dominate the site and therefore the entire market.

The other line along which plant location theory has developed emphasizes differential demand factors with sufficient factor supply elasticity that differential factor costs are inconsequential. In this framework, sellers locate themselves in a way that optimizes their access to a specific subset of the buyers who are scattered over space.

The two approaches can be integrated by viewing the plant location decision as being based on a maximum profit calculation, which is the difference between total revenues (demand determined) and total costs (supply determined). The optimal location for any given firm may be neither the point of maximum sales, nor the point of least cost, but rather some compromise between the two. Furthermore, the possibility exists that a number of optimal locations exist, given the possible geographic variations of demand and cost.

A further broadening of the range of possible plant locations occurs when one allows the locator's objective function to include noneconomic as well as economic factors. As Greenhut (1951) stated:

(1) The definition of the locator's objective in plant location must be broader than the simple claim that individuals seek maximum profits.

(2) The free choice of location, by a rational individual, can be explained under the postulate that individuals seek maximum satisfactions in selecting their plant site.

(3) The factors of location may then be broadened to include personal considerations, which are unrelated to maximum profits.

Given that a firm has initially chosen a specific location, what factors would lead this firm to alter its location? The model of firm relocation that we will build is based on the premise that the firm's relocation is part of its strategy of profit maximization, set in the context of satisfying other, nonpecuniary objectives of the managers/owners. Consider a set of firms in a particular industry. The profit maximization problem of firm $i$ in region $j$ results in a profit function, specific to the firm:

$$
E_{i j}=E_{i j}\left(X_{i}, Z_{j}\right)
$$

where $E_{i j}$ denotes a target rate of profits by firm $i$ in region $j, X_{i}$ denotes firm-specific factors for firm $i$, and $Z_{j}$ denotes location specific factors in location $j$.

It is assumed that firms (who are all potential migrants) behave as if they continuously monitor their actual profits relative to a fixed target threshold. The threshold is determined by a combination of industry standards and the extent to which the owner/manager of the firm is willing to sacrifice pecuniary for nonpecuniary gains. The firm is assumed to react strategically to the inequality

$$
E_{i j}\left(X_{i}, Z_{j}\right)<E_{i}(y),
$$

where y denotes a vector of observed indicators of average profits in the industry. Note that it is to some function of these average profits that the firm reacts and each firm may perceive a common set of indicator profits differentially. Obviously, given some initial equilibrium an inequality arises in equation (2) only if the $X_{i}$ or $Z_{j}$ factor changes or if there is a change in the fashion in the calculation of the target profit, $\mathrm{E}_{\mathrm{i}}$.

When the inequality expresser in equation (2) persists over time for a specific firm, standard theory suggests that the firm will leave the industry, change its location, or adjust output and/or input combinations. Firms which relocate do so in order to change $\mathrm{X}_{\mathrm{i}}$ and/or $\mathrm{Z}_{\mathrm{j}}$ in the appropriate directions with sufficient magnitude to make the target earnings rate accessible.

In order to test this theory, we propose to utilize the type of model that has become fairly standard in research on human migration. We will model gross migration flows of firms, identifying both point of origin and point of destination. Our model therefore describes the factors that simultaneously explain why firms leave areas with a set of characteristics and why they are attracted to other areas with another set of characteristics. Note that, by deciding to construct and test a model of aggregate business migration, we concentrate on the impact of location specific factors rather than on the impact of firm specific factors. Work with microdata would conversely focus relatively more on firm specific factors.

The general form of the model we estimate is as follows:

$$
\begin{aligned}
& \mathrm{FM}_{\mathrm{jk}}=\mathrm{f}(\text { Origin Characteristics, } \\
& \text { Destination Characteristics, Distance), }
\end{aligned}
$$


where $F M_{j k}=$ total number of firms moving from region $\mathbf{j}$ to region $\mathbf{k}$ over a given interval of time.

Both origin and destination characteristics should include factors that affect the profits of a firm and as well those factors that affect the nonpecuniary objectives of the locator. As our theory suggests, factors affecting the profits of a firm should be oriented to both supply and demand factors. Supply type measures include either direct or proxy measures of the cost of factor inputs, while demand type measures include direct or proxy measures of effective demand in an area. Specifying the factors that affect the nonpecuniary objectives of the firm owner/manager is more problematic. However, in theory at least, some measure(s) of the "regionspecific" quality of life should be included in the model. Finally, the distance between an origin and a destination will serve as a proxy measure of both the economic and the psychic cost of moving.

\section{Data and Data Development}

The data used in this analysis were compiled from the Dun's Market Identifiers (DMI) file developed by the Dun and Bradstreet Corporation (D and B). The file contains records for U.S. firms which either have requested a credit rating from $D$ and B or another firm has requested a credit rating on them. Each record includes the firm's address, the standard industrial classification (SIC), and ownership status (corporation headquarters, branch or noncorporate single-unit operation). For the purpose of this study, a special relocation file was created from the master DMI file. The special file contains only those firms which meet the following criteria: 1) the firm is classified in a manufacturing SIC; 2) the firm's record was classified as a corporate headquarters; 3) the firm changed region of its operation between 1970 and 1980. For this study, a region is a census-defined division. A total of 249 firms met these criteria.

These criteria were used to develop the file for a number of reasons. The choice of limiting the study to only firms in manufacturing industries was made to insure some homogeneity in the scope of the study and the associated data to be gathered. Our study was confined to firms where the relocation decision would not take the form of creating a branch plant which might have a large portion of the firm's production activity farmed out to that plant. Thus, relocation of only firm headquarters were taken in our file. Finally, the choice of the 10-year period was a more or less arbitrary one, based partly on our desire to ease the process of data gathering and partly on our desire to chose a period sufficiently long to assure a sufficiently large sample of movers.
Recording firm migration with these data presents a number of potential pitfalls. If a firm changed its region of operation and simultaneously changed its name or its ownership, the relocation would go unrecorded on the DMI file. In fact, the DMI file would record the death of one firm and the birth of another, where in fact one firm had simply changed location. A related problem occurs in instances where firms are born after 1970 but relocate prior to 1980, or firms in existence in 1970 relocate prior to 1980 but subsequently go out of existence. Finally, a firm which changes location twice during the decade will be recorded as having moved only once, or not at all if its second move was back to the region of origin. In none of these instances would the DMI file record a firm migration. To summarize, the DMI file provided the lower bound for measuring industrial firm mobility. Not only has each decision that we made regarding the sample lowered the sample size, but the additional biases inherent in the data set have also had the effect of systematically lowering the sample size. This may help explain the seemingly low sample size of 249 . It should be noted that analagous problems exist in computing human migration flows, particularly from U.S. Census data. For more information on using the DMI file, see Birch (1979) and Miller (1979).

The overall pattem of business movement can be seen in Tables 1 and 2, which display out- and inmigration of manufacturing firms by census region. Of the 249 firms meeting our criteria that migrated between 1970 and 1980,120 or nearly $50 \%$ left the Middle Atlantic states (comprised of New York, New Jersey, and Pennsylvania). The East North Central region ranked second in terms of the number of firms lost, after which the number of migrating firms falls off considerably.

The South Atlantic region received more firm migrants than any other region, although the New England region ranked a close second. After these two regions, inmigration of firms was spread fairly evenly among the remaining regions.

\section{Model Specification}

The model chosen to estimate is a close relative of a number of region-to-region human migration models (see Greenwood (1975) for a summary of such models). It is basically a gravity model, with variables chosen to act as proxies for pecuniary and nonpecuniary determinants of migration, as discussed in Section II. Our dependent variable is an aggregate measure of only those firms that actually changed their headquarters region. This specification restricts the model in an important fashion, as all migrating firms are treated alike. Therefore, no account is taken 
Table 1

Outmigration of Manufacturing Firms by Census Region

\begin{tabular}{ccc} 
Region & $\begin{array}{c}\text { Number of Firms } \\
\text { Outmigrating }\end{array}$ & $\begin{array}{c}\text { Percent of Total } \\
\text { Outmigrating }\end{array}$ \\
\hline
\end{tabular}

New England

11

Middle Atlantic

120

48.2

South Atlantic

14

East North Central

47

18.9

East South Central

20

8.0

West North Central

18

7.2

West South Central

5

2.0

Mountain

2

0.8

Pacific

12

4.8

Total 
An Aggregate Model of Manufacturing Firm Migration

Table 2

Inmigration of Manufacturing Firms by Census Region

Region

New England

Middle Atlantic

South Atlantic

East North Central

East South Central

West North Central

West South Central

Mountain

Pacific

Total

\begin{tabular}{l} 
Number of Firms \\
Inmigrating \\
Since 1970 \\
\hline
\end{tabular}

62

15

65

25

13

15

20

16

18

\section{Percent of Total Inmigrating Firms}


of the differential employment levels among firms. Further, this analysis does not consider intraregional migration, nor does it consider the differences between migrants and nonmigrants. By focusing only on migrants, the study precludes evaluation of the initial stage of the migration decision.

The model that we estimated is specified with the following variables:

$$
F M_{j k}=f\left(D_{j k}, L_{j}, L_{k}, E_{j}, E_{k}, S_{j}, S_{k}, E n_{j}, E n_{k}\right),
$$

where

$F M_{j k}=$ firm migration: total manufacturing firms moving headquarters from Census division $\mathrm{j}$ to Census division $\mathrm{k}$ between 1970 and $1980 ;+0.1$ was added to each of the dependent variables since they were used in $\log$-log regressions and for some observations, their alue would otherwise be zero; source: Dun and Bradstreet.

$D_{\mathbf{j k}}=$ distance: the approximation of the distance in miles between the population centroid of region $\mathrm{j}$ and the population centroid of region $\mathbf{k}$.

$\mathrm{L}_{\mathrm{j}} \quad=$ labor force: the size of the labor force in region $\mathrm{j}$ in 1970; likewise for region $\mathrm{k}$; source: Bureau of Labor Statistics.

$\mathrm{E}_{\mathrm{j}}$ = earnings: the ratio of earnings per worker in manufacturing industries in region j, 1970; likewise for region $\mathbf{k}$; source: Bureau of Labor Statistics.

$S_{j} \quad=$ social disorganization: a composite indicator of social well being, attempting to measure the social stability of region $\mathrm{j}, 1970$; likewise for region k; source: Smith (1974).

$\mathrm{En}_{\mathrm{j}}$ = environment: a composite indicator of the cost and quality of structures, the quality of streets and sewers, and the extent of air. pollution and open spaces in region j, 1970; likewise for region k; source: Smith (1974).

The distance variable is included as a proxy for the cost of moving, which certainly would enter into the profit maximization calculus of a potential migrant firm. In addition, distance is thought to be a measure of the psychic costs of moving to the owner/manager. The expected impact of this variable, emanating consistently from both phenomena that it is designed to measure, is negative.

The labor force variables serve as proxies for two forces, one a supply side force, and one demandside force. They represent the size of the market in origin and destination regions. As such, $\mathrm{L}_{\mathrm{j}}$ would be expected to have a negative sign, and $\mathrm{L}_{k}$ a positive sign, because presumably firms seek to locate as close as possible to their markets. The size of the labor force, however, is also a measure of the pool from which the firm hires its workers. The larger this pool, the more attractive would be the region to the firm. For both reasons these variables are expected to be negatively related the migrant flow for $\mathrm{L}_{j}$ and positive for $\mathrm{L}_{\mathbf{k}}$. Both $\mathrm{L}_{\mathrm{j}}$ and $\mathrm{L}_{\mathbf{k}}$ are beginningof-period values (1970). This will allow us to avoid simultaneity problems that might be associated with labor force and migration data when they are measured contemporaneously.

Like labor force, earnings per worker is a proxy for several separate factors, each of which would enter into the profit determination for the firm. As a cost of production, one would expect $E_{j}$ to exert a positive push on firms exiting a region, while $E_{k}$ would be expected to have a negative pull on firms entering a region. However, the eamings ratio, in a competitive environment, is also a proxy for both worker productivity and effective per capita spending capacity. As such, one would expect it to behave in a way exactly opposite from the cost of production: the sign on $E_{j}$ would be expected to be negative, while that on $E_{k}$ would be expected to be positive. Overall, we are unsure of which force is likely to be stronger and this becomes an empirical rather than a theoretical question. As with labor force, we use beginning of period data on earnings, assuming that there is a behavioral lag in reacting to regional differences in earnings rates through regional firm migration.

The most difficult measures to define are those that deal with the nonpecuniary benefits of living in a region. One problem in this regard is the incomparability of individual utility functions. It is therefore problematic to identify regional characteristics that would be considered universally beneficial. Another problem is that, by their nature, nonpecuniary benefits are difficult to measure because they are often not distributed through markets. We have chosen two variables that have been developed as composite measures of broadly defined aspects of "quality of life". The social disorganization variable, $S$, combines measures of the incidence of personal pathologies, overcrowding, and criminal activity. Higher values of this variable mean a greater incidence of these "bads". We expect a positive sign to accompany this variable for origin regions, a negative sign for destination regions.

Our second nonpecuniary benefits variable, En, measures various aspects of environmental quality. Included are measures of housing cost and quality, the 
extent and quality of streets and sewers, air pollution, and open space. Higher values of this variable indicate higher environmental quality overall. Therefore, a priori, we expect a negative sign on this variable for origin regions, a positive sign for destination regions.

\section{Results of the Estimation}

The results of estimating the model are reported in Table 3. As far as providing empirical support for our model of business migration, these results are quite strong but not perfect. Probably the strongest pattern to emerge is the asymmetry between the impacts of origin characteristics and destination characteristics on aggregate firm migration. All variables that measure conditions at the origin of the relevant migration streams were statistically significant with $95 \%$ confidence or better, analogous variables measured at destinations exhibited coefficients which were not as statistically significant.

These results are reminiscent of the seminal human migration study by Lowry (1966), although they lead us to a conclusion just opposite that of Lowry. Lowry concluded that for inter-metropolitan migration, destination characteristics predominate over origin characteristics in their relative ability to explain migration flows. Our results suggest that, for aggregate manufacturing firm flows, origin characteristics dominate destination characteristics in explanatory power.

Regarding the behavior of specific variables in our model, our results lead us to conclude that firms tended in the 1970's to leave the high wage and highly populated regions. This movement is inferred from the positive and significant coefficients on both the origin earnings rate, $E_{j}$, and the origin labor force size, $L_{j}$. The sign of the coefficient on the earnings rate variable leads us to believe that higher factor costs of labor are more important to potential business migrants than are the (theoretically) higher labor productivity and spending capacity levels associated with high earnings rates. While it is logical to expect firms leaving high wage regions to seek destinations characterized by lower wages, our results support the opposite conclusion. The sign on the destination earnings rate, $\mathrm{E}_{\mathrm{k}}$, is positive, giving rise to speculation that the spending capacity and labor productivity of the destination regions are more important, although this force is not statistically significant.

The only sign opposite of a priori expectations is that of the coefficient of $L_{j}$, the origin labor force variable. We expected a negative sign, believing that firms would not be inclined to leave areas with large market areas and/or large labor pools. Instead, it appears that firms systematically depart such regions. We expect that this departure may be caused by a "size effect". In our gravity model, the size of the labor forces are measures of the mass of the regions. Regions with greater mass will exert more pressure for simultaneous interactions, hence the positive effects of both $L_{j}$ and $L_{k}$.

As expected, it was found that distance is a statistically significant deterrent to the interregional migration of manufacturing firms. As we indicated earlier, this deterrent effect may be due to at least two factors. Firstly, distance is a proxy for the pecuniary costs of moving a business establishment and could, therefore, be expected to have a negative relationship to the volume of such movement. In addition, distance is a proxy for the psychic cost to the owner/management of a firm, again leading to the expectation of a negative coefficient. Yet another reason might help explain the negative sign on the distance variable. Having established regional market areas, firms that are motivated to change location for other reasons may attempt to stay as close as possible to their initial location in order to continue serving the same market. If a short-distance move can sufficiently alter the determinants of a firm's profits while allowing it continued access to an already established market, we would expect a negative distance effect solely for this reason.

The two variables that were included to measure quality of life conditions performed as expected for origin regions, while not providing significant explanatory power regarding destination regions. The social disorganization variable, $S_{j}$, exhibited a positive and significant relationship to firm migration, when measured for the origin region. This relationship was as we expected. The same variable measured at the destination, $S_{\mathbf{k}}$, while of the expected (negative) sign, had a t-value considerably less than one. The other quality-of-life variable, measuring environmental quality, $\mathrm{En}_{\mathrm{j}}$, had a negative and significant coefficient for origin regions, as expected. This sign negative coefficient can be interpreted to mean that firms leave areas with poor environmental quality in systematically greater numbers. From our results, however, it is not possible to infer that firms seek out regions with high quality environments, since the coefficient on $\mathrm{En}_{\mathbf{k}}$ was found to be statistically insignificant.

These results are not as powerful as we would like in terms of our explanation of aggregate firm migration. The consistently significant results for 
Table 3

Regression Results of Estimation of the Model

Expected

Variable

$\underline{\text { Sign }}$

$\underline{\text { Coefficient }}$

t-Value

Intercept

$-48.117$

$-4.304$

$\mathrm{L}_{\mathrm{j}}$

1.886

4.461

L

0.039

0.105

$\mathrm{D}_{\mathbf{j k}}$

$-0.660$

$-2.485$

$\mathbf{E}_{\mathbf{j}}$

$?$

5.104

1.974

$\mathbf{E}_{\mathbf{k}}$

$?$

2.482

1.589

$\mathbf{S}_{\mathbf{j}}$

$+$

1.939

2.589

$\mathbf{S}_{\mathbf{k}}$

$-0.780$

$-0.511$

Enj $_{\mathbf{j}}$

$-2.558$

$-3.330$

$\mathrm{En}_{\mathbf{k}}$

0.098

0.062

$\mathrm{R}^{2} \quad=0.463$

$F(9,64) \quad=5.94$ 
origin-region variables and the strikingly insignificant results of destination-region variables need further explanation. The notion that firms systematically calculate their profit potential at their origin and, having made their decision to relocate, chose their destination randomly is not an acceptable conclusion. A partial explanation can be found by examining the full set of specific region-to-region flows. This information is found in Table 4, and shows that the flow of firms is dominated by the Middle Atlantic region as an origin, with 120 of a total of 249 migrating firms, and that the two adjacent regions - New England and South Atlantic -- received 97 of these firms. One origin and two specific, short distance flows are quite important in our data, and it therefore should be no surprise that origin characteristics and distance have such large explanatory power in our model. Further exploration of these findings is certainly warranted.

\section{Summary and Conclusions}

The purpose of this research was to contribute to the sparse literature regarding the interregional migration of business firms. Data derived from the Dun and Bradstreet Dun's Market Identifier file were used to develop estimates of the aggregate interregional flow of manufacturing firms. The framework for the analysis included a firm profit calculus that includes interregional migration as a possible determinant. Various proxies of variables that are determinants of profits, at both the origin and destination, were specified in the model of origin to destination migration.

The results of estimating the model generally supported our framework, at least to the extent that profit proxies can be used to explain systematically what kind of regions firms leave. These results suggest that firms changing headquarters region tend to leave regions with large agglomeration effects, as well as regions where factor costs are relatively high. Finally, firms that move tend to leave areas whose social environment is relatively unstable. All of these results were recorded with at least $95 \%$ statistical confidence.

In contrast, the only variable that included destination information and also attained statistical significance was the distance variable. As expected, distance was found to be a significant deterrent to interregional migration. Otherwise, all information concerning destination regions was found to be statistically insignificant in explaining the interregional migration of firms. While it is far too early to draw such a conclusion firmly, our evidence suggests origin characteristics, and not destination characteristics, determine the size of the flow of firms between regions. Whether the expelling force of regions truly dominates the attracting force of regions in this phenomenon should be the subject of continued research.

\section{REFERENCES}

Birch, D. "Using the Dun and Bradstreet Data," presented at the Dun and Bradstreet Dun's Market Identifiers File Data Users Conference, Washington, D.C. 1979.

Carlton, D. "Why New Firms Locate Where They Do: An Econometric Model." In Interregional Movements and Regional Growth. Edited by W. Wheaton. Washington, D.C.: The Urban Institute, 1981.

- "The Location and Employment Choices of New Firms: An Econometric Model with Discrete and Continuous Endogenous Variables." Review of Economics and Statistics. 115:2 (August, 1983).

Greenhut, M. " Observations of Motives to Plant Location." Southern Economic Journal. 18 (1951).

- "Integrating the Leading Theories of Plant Location." Southern Economic Journal. 18 (1952).

Greenwood, M. "Human Migration: Theory, Models, and Empirical Studies." Journal of Regional Science. 25:4 (November 1985). . "Research on Internal Migration in the United States: A Survey." Journal of Economic Literature. 13:2 (June, 1975).

Lowry, I. Migration and Metropolitan Growth: Two Analytical Models. Los Angeles: Institute of Government and Public Affairs, 1966.

Miller, J. "Research with Dun and Bradstreet Data," presented at the Dun and Bradstreet Dun Market Identifiers File Data Users Conference, Washington, D.C. 1979.

Nakosteen, R. and M. Zimmer. "Determinants of Regional Migration by Manufacturing Firms." Economic Inquiry. 25:2 (April, 1987).

Oster, S. "Industrial Search for New Locations: An Empirical Analysis," Review of Economics and Statistics. 111:2 (May, 1979).

Smith, D. The Geography of Social Well-Being in the U.S. New York: McGraw-Hill Publishing Company, 1974. 


\title{
Table 4
}

Interregional Firm Migration Flows

1970

\author{
1980 Region
}

N.E. M.A. S.A. E.N.C. E.S.C. W.N.C. W.S.C. MTN. PAC.

$\begin{array}{llllllllll}\text { N.E. } & - & 2 & 2 & 3 & 1 & 1 & 1 & 0 & 1 \\ \text { M.A. } & 56 & -- & 41 & 9 & 5 & 1 & 7 & 1 & 0 \\ \text { S.A. } & 1 & 5 & -- & 0 & 3 & 3 & 0 & 1 & 1 \\ \text { E.N.C. } & 1 & 4 & 12 & -- & 4 & 6 & 8 & 7 & 5 \\ \text { E.S.C. } & 2 & 0 & 9 & 2 & -- & 1 & 1 & 2 & 3 \\ \text { W.N.C. } & 1 & 1 & 0 & 7 & 0 & - & 4 & 1 & 4 \\ \text { W.S.C. } & 0 & 0 & 0 & 2 & 0 & 1 & - & 1 & 1 \\ \text { MTN. } & 0 & 0 & 0 & 0 & 0 & 2 & 0 & -- & 0 \\ \text { PAC. } & 1 & 3 & 1 & 2 & 0 & 0 & 2 & 3 & -\end{array}$

$\begin{array}{ll}\text { N.E. } & =\text { New England } \\ \text { M.A. } & =\text { Middle Atlantic } \\ \text { S.A. } & =\text { South Atlantic } \\ \text { E.N.C. } & =\text { East North Central } \\ \text { E.S.C. } & =\text { East South Central } \\ \text { W.S.C. } & =\text { West South Central } \\ \text { MTN. } & =\text { Mountain } \\ \text { PAC. } & =\text { Pacific }\end{array}$

